\title{
Perpaduan Metode Newton-Raphson Dan Metode Euler Untuk Menyelesaikan Persamaan Gerak Pada Osilator Magnetik
}

\author{
Riza Ibnu Adam \\ Universitas Singaperbangsa Karawang \\ Email : riza.adam@staff.unsika.ac.id
}

Received February 1, 2017; Revised March 20, 2017; Accepted March 23, 2017

\begin{abstract}
Abstrak
Telah dilakukan analisis untuk memperoleh solusi persamaan differensial nonlinear dari osilator magnetik dengan memadukan metode Newton-Raphson dan metode Euler. Nilai parameter gaya magnetik $k$ diperoleh dengan menggantungkan magnet seperti ayunan matematis. Dalam model numerik, metode Newton-Raphson diperoleh nilai jarak kesetimbangan antara magnet statis 1 dengan magnet utama sebesar 0,01512559816833 m. Adapun dari metode Euler didapatkan model osilator magnetik mulai nonlinear pada saat diberikan simpangan 0,010524 m. Hasil analisis menunjukkan besarnya masukan awal sangat berpengaruh terhadap kestabilan sistem osilator magnetik di waktu selanjutnya. Perpaduan metode Newton-Raphson dan metode Euler dapat digunakan untuk menyelesaikan persamaan differensial nonlinear osilator magnetik.
\end{abstract}

Kata kunci: Nonlinear, Osilator Magnetik, Metode Newton-Raphson, Metode Euler

\section{Newton-Raphson And Euler Methods Merger To Solving Motion Equation On The Magnetic Oscillator}

\begin{abstract}
An analysis has been carried out to obtain the solution of a nonlinear differential equations for a magnetic oscillator by combining Newton-Raphson and Euler methods. The parameter of magnetic force $k$ was obtained by hanging the magnet as a pendulum. On the numerical model, the NewtonRaphson method give the equilibrium distance between the static magnet and the main magnet $0.01512559816833 \mathrm{~m}$. The Euler method for modelling the dynamic of the magnetic oscillator showed that nonlinear effect sets in when the initial displacement is $0.010524 \mathrm{~m}$. The analysis shows that the value of the initial condition is determinant on the stability of the magnetic oscillator system at a later stage. The combination of Newton-Raphson method and Euler method can be used to solve nonlinear differential equation of the magnetic oscillator.
\end{abstract}

Keywords: Nonlinear, Magnetic Oscillator, Newton-Raphson Method, EulerMethod

\section{PENDAHULUAN}

Osilator magnetik merupakan sebuah sistem osilasi yang memanfaatkan magnet sebagai pengganti pegas. Sistem osilator magnetik terdiri atas dua buah magnet statis (tidak berosilasi) dan sebuah magnet utama (berosilasi). Pada sistem tersebut magnet utama dipasang sekutub dan berada di antara magnet statis. Pada saat terjadi getaran, magnet utama yang berada di tengah akan mengalami osilasi akibat terjaga oleh kedua magnet statis yang berada di ujung.
Sistem osilator magnetik telah diterapkan pada sensor getaran berbasis induksi elektromagnetik (Hartono, dkk. 2010). Pada sensor tersebut, getaran dimanfaatkan untuk menggerakkan magnet supaya berosilasi. Perubahan medan magnet di dalam kumparan akan menghasilkan medan listrik. Namun, penggunaan osilator magnetik pada sensor tersebut tidak dapat bekerja secara optimal. Hal ini dikarenakan belum dapat diperolehnya kurva kalibrasi antara besar osilasi terhadap tegangan. Untuk menganalisis hal tersebut, maka perlu ditinjau dinamika sistem osilasinya. 


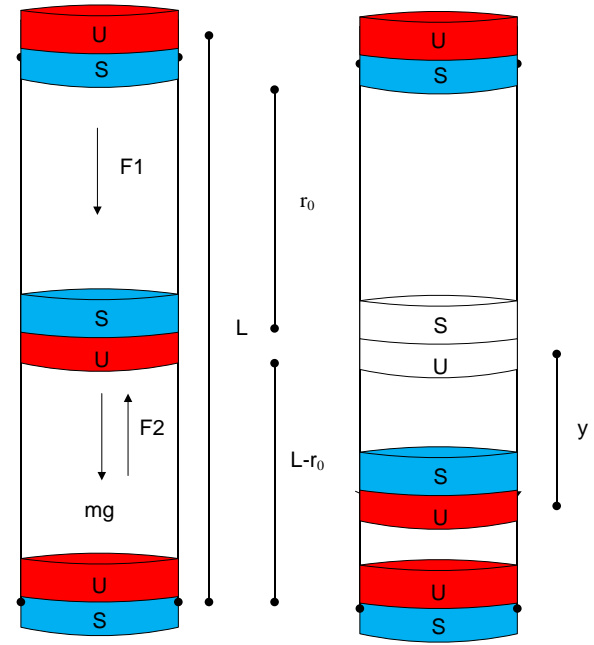

Gambar 1. Osilator magnetik

Sistem osilator magnetik dapat dinyatakan sebagai persamaan diferensial nonlinear orde-2. Nonlinearitas dari sebuah sistem menjadikan sistem yang ditinjau cukup sulit dicari solusinya. Solusi persamaan diferensial dapat diselesaikan dengan metode analitik maupun metode numerik. Metode analitik menghasilkan solusi eksak, namun tidak dapat menyelesaikan persamaan diferensial yang bersifat nonlinear. Adapun metode numerik merupakan solusi aproksimasi yang dapat dilakukan secara langsung tanpa penyederhanaan parameter fisis, tetapi memerlukan fungsi coba standar yang ditentukan dengan metode analitik (Bronson \& Costa, 2007). Oleh karena itu, diperlukan perpaduan antara metode analitik dan metode numerik untuk memodelkan dinamika osilator magnetik.

Terdapat dua metode yang digunakan untuk memodelkan dinamika osilator magnetik yaitu metode Newon-Raphson dan metode Euler. Metode Newton-Raphson merupakan metode untuk menyelesaikan akar-akar persamaan (J. Aminuddin, 2008). Metode ini telah digunakan untuk menyelesaikan sistem nonlinear pada medan magnet statis (Kuczmann, 2008). Metode berikutnya adalah metode Euler. Metode ini merupakan metode untuk menyelesaikan persamaan diferensial (Kiusalaas, 2005). Metode ini telah digunakan untuk menyelesaikan persamaan diferensial Sturm-Liouville (Mardiana, 2010).

Penelitian yang telah dilaksanakan bertujuan untuk mendapatkan solusi persamaan diferensial non linear pada sistem osilator magnetik. Metode analitik digunakan untuk mengungkapkan model dinamika sistem osilator magnetik ke dalam bentuk persamaan diferensial. Solusi persamaan diferensial tersebut diselesaikan menggunakan dua metode numerik, yaitu metode Newton-Raphson yang dilanjutkan dengan Metode Euler. Metode Newton-Raphson digunakan untuk mengetahui jarak antara magnet utama dengan magnet statis pada saat keadaan seimbang $(y=0)$. Adapun metode Euler digunakan untuk mengetahui model perubahan simpangan $(y)$ dan kecepatan (v) pada saat diberi gangguan. Keberhasilan penelitian ini diharapkan berkonstribusi pada perkembangan sensor getaran berbasis osilator magnetik.

\section{METODE}

Penelitian ini dimaksudkan untuk memperoleh dinamika nonlinear pada osilator magnetik. Berdasarkan hukum kedua Newton magnet utama akan mengalami gaya akibat gravitasi dan gaya magnetik oleh kedua magnet statik sebagaimana yang dituliskan pada persamaan (1).

$$
\begin{gathered}
F_{1}+m g=F_{2}, \\
F=\frac{\mu_{0} p_{1} p_{2}}{4 \pi r^{2}},
\end{gathered}
$$

dengan $F$ merupakan gaya magnetik, $\mu_{0}$ permeabilitas ruang bebas dan $P_{1}, P_{2}$ adalah kuat kutub magnet (Longair, 2003). Persamaan (2) dapat dituliskan sebagai berikut

$$
F=\frac{k}{r_{0}^{2}}
$$

dengan $k$ merupakan sebuah parameter konstan. Berdasarkan persamaan (1) dan (3) serta mengacu pada Gambar 1, maka diperoleh 
Jurnal Pendidikan Fisika dan Keilmuan (JPFK) Vol 3 No 1 Maret 2017, hal 13-18

Avaliable online at : http://e-journal.unipma.ac.id/index.php/JPFK

Print ISSN: 2442-8868, Online ISSN: 2442-904x

persamaan gaya pada keadaan setimbang sebagai berikut :

$$
\frac{d^{2} y(t)}{d t^{2}}=\frac{k}{m}\left(\frac{1}{\left(r_{0}+y(t)\right)^{2}}-\frac{1}{\left(L-r_{0}-y(t)\right)^{2}}\right)+g,
$$

dengan $m$ massa magnet, $g$ adalah percepatan gravitasi, $r_{0}$ jarak antara magnet statis 1 dan magnet osilasi pada saat setimbang, serta $L$ jarak antara magnet statis 1 dan magnet statis 2 , serta (y) adalah simpangan.

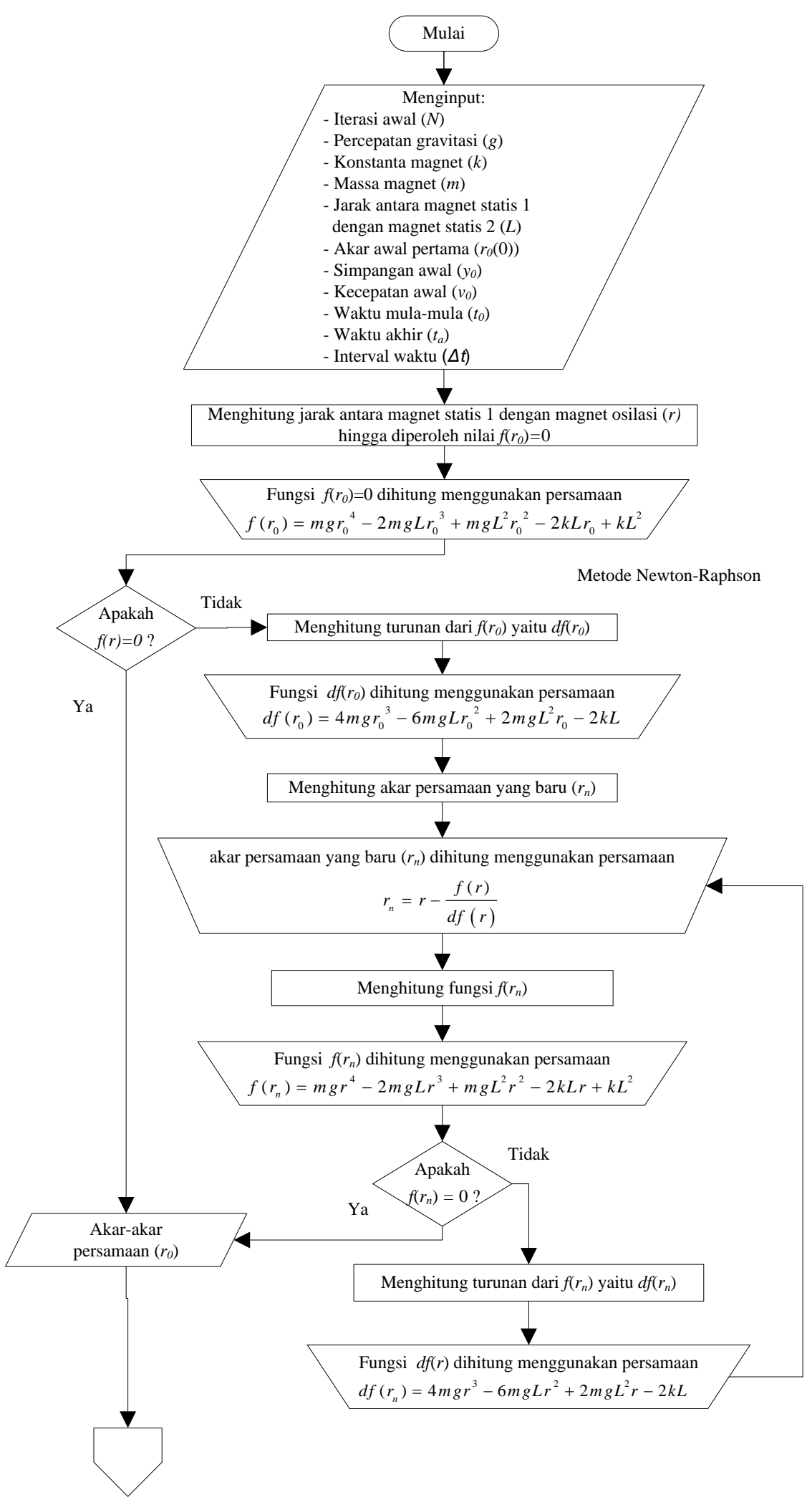


Jurnal Pendidikan Fisika dan Keilmuan (JPFK) Vol 3 No 1 Maret 2017, hal 13-18

Avaliable online at : http://e-journal.unipma.ac.id/index.php/JPFK

Print ISSN: 2442-8868, Online ISSN: 2442-904x

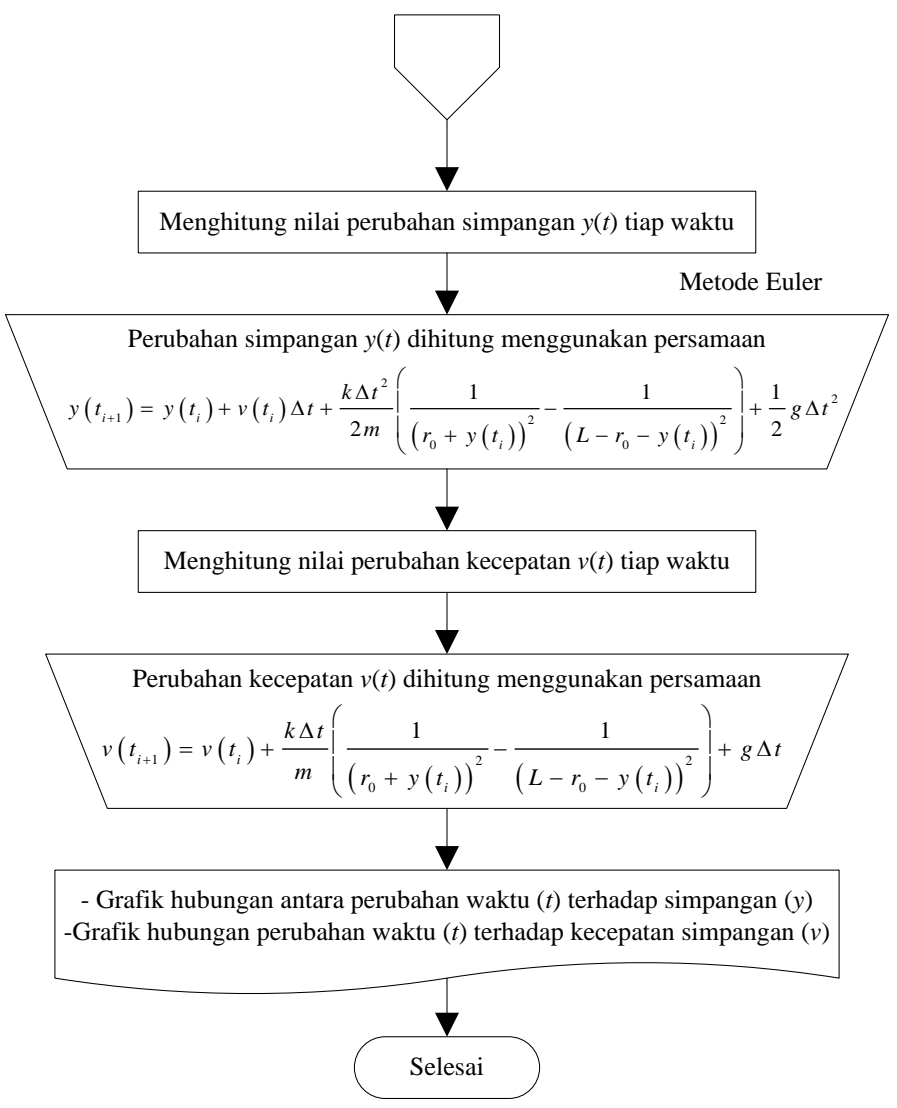

Gambar 2. Algoritma program

Perancangan program dilakukan menggunakan software MATLAB 7.0. Metode numerik yang digunakan dalam penelitian ini adalah metode Newton-Raphson dan Metode Euler. Metode Newton-Raphson digunakan untuk memperoleh nilai $r_{0}$ magnet begerak pada saat sistem tidak diberi gangguan. Adapun metode Euler digunakan untuk menentukan posisi dan kecepatan setiap saat, ketika $r_{0}$ telah diperoleh dan sistem diberi gangguan $y$. Perancangan program dimulai dengan pembuatan algoritma program seperti pada gambar 2.

\section{HASIL DAN PEMBAHASAN}

Perancangan program dilakukan berdasarkan algoritma metode Newton-Raphson dan metode Euler. Metode Newton-Raphson digunakan untuk memperoleh nilai jarak antara magnet statis 1 dan magnet osilasi pada saat sistem tidak diberi gangguan $\left(r_{0}\right)$. Nilai $r_{0}$. diperoleh dengan menginput nilai iterasi awal $(N)$, percepatan gravitasi $(g)$, konstanta magnet $(k)$, massa magnet $(m)$, jarak antara magnet statis 1 dengan magnet statis $2(L)$ dan akar awal pertama $\left(r_{0}(0)\right)$ masing-masing sebesar $10,9,8$ $\mathrm{m} / \mathrm{s}^{2}, 0,008173 \mathrm{Nm}^{2}, 0,109002 \mathrm{Kg}, 0,03003 \mathrm{~m}$, $0,03003 \mathrm{~m}$. Hasil perhitungan nilai $r_{0}$ dengan metode Newton-Raphson diperlihatkan pada Tabel 1. Nilai $r_{0}$ didapatkan pada iterasi ke-5 ketika $f\left(r_{0}\right)=0$, yaitu sebesar 0,01512559816833 $\mathrm{m}$. Besarnya nilai $r_{0}$ yang dihasilkan berada pada batas $\quad \frac{1}{2} L \leq$. Hal ini dikarenakan magnet utama dipengaruhi oleh gaya gravitasi dan gaya tolak dari kedua magnet statis.

Tabel 1. Hasil Perhitungan nilai $r_{0}$.dengan metode Newton-Raphson.

\begin{tabular}{cccc}
\hline Iterasi ke- & $r_{0}(i)$ & $f\left(r_{0}\right)$ & $f\left(r_{0}+1\right)$ \\
\hline 1 & 0,03003000000000 & $-0,00000737041876$ & $-0,00049087038000$ \\
\hline 2 & 0,01501500000000 & 0,00000005429526 & $-0,00049087038000$ \\
\hline 3 & 0,01512561017046 & $-0,00000000000589$ & $-0,00049097692736$ \\
\hline 4 & 0,01512559816833 & $-0,00000000000000$ & $-0,00049097691580$ \\
\hline 5 & 0,01512559816833 & 0 & $-0,00049097691580$ \\
\hline
\end{tabular}




\section{Jurnal Pendidikan Fisika dan Keilmuan (JPFK) Vol 3 No 1 Maret 2017, hal 13-18 \\ Avaliable online at : http://e-journal.unipma.ac.id/index.php/JPFK \\ Print ISSN: 2442-8868, Online ISSN: 2442-904X}

Setelah nilai $r_{0}$ diketahui selanjutnya dilakukan pemodelan perubahan simpangan dan kecepatan gerak osilator magnetik dengan metode Euler. Nilai $r_{0}$ yang telah diketahui disubsitusi ke persamaan (4) yang kemudian digunakan untuk memodelkan perubahan simpangan dan kecepatan gerak osilator tersebut. Setelah mencoba mengubah parameter simpangan awal maka diperoleh batas transisi linear ke nonlinear $y_{0}=0,010524 \mathrm{~m}$. Hasil ini diperoleh dengan cara memvariasikan perubahan simpangan awal yang ditentukan tiap $0,01 \mathrm{~m}, 0,001 \mathrm{~m}, 0,0001 \mathrm{~m}, 0,00001 \mathrm{~m}$ dan $0,000001 \mathrm{~m}$.

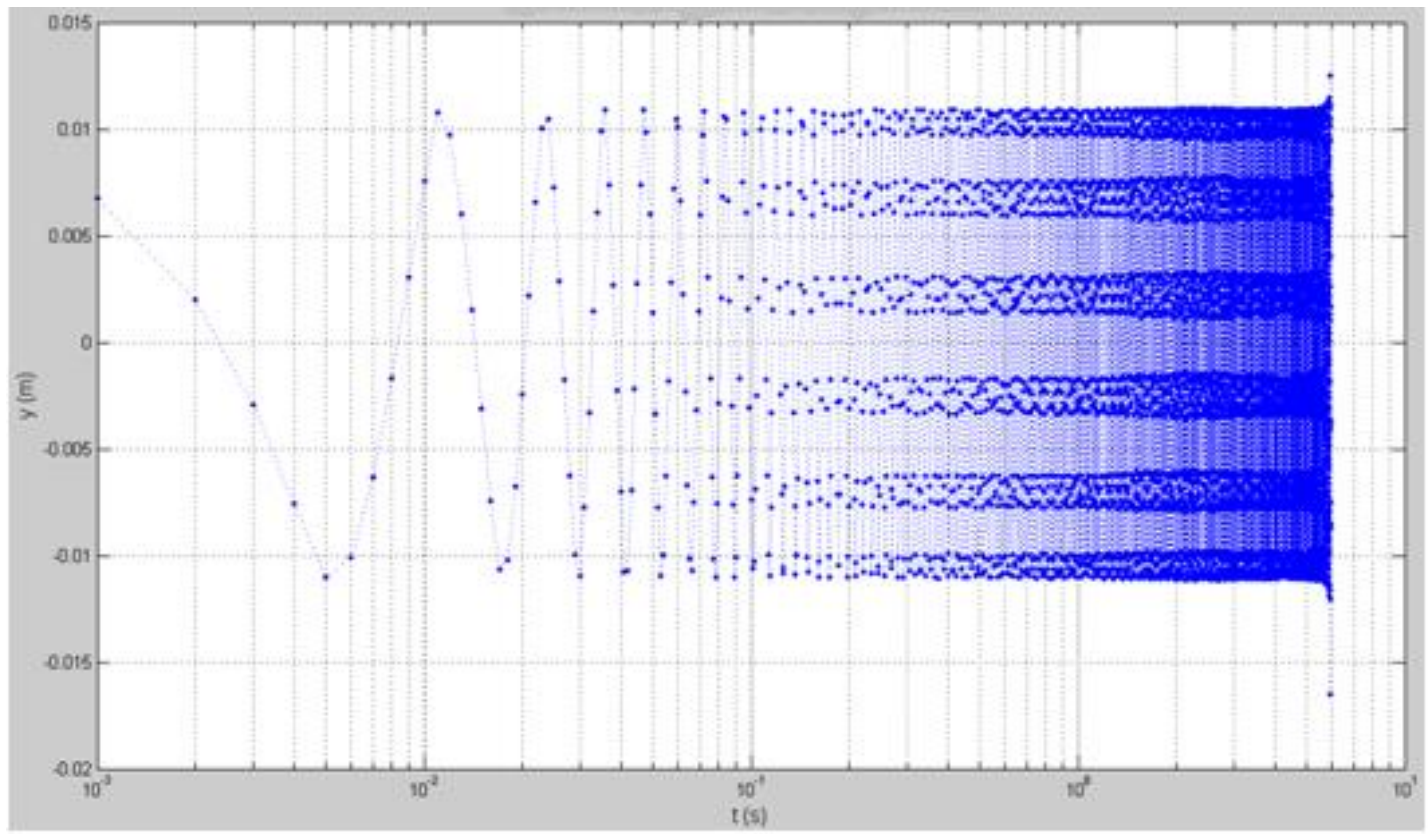

(a)

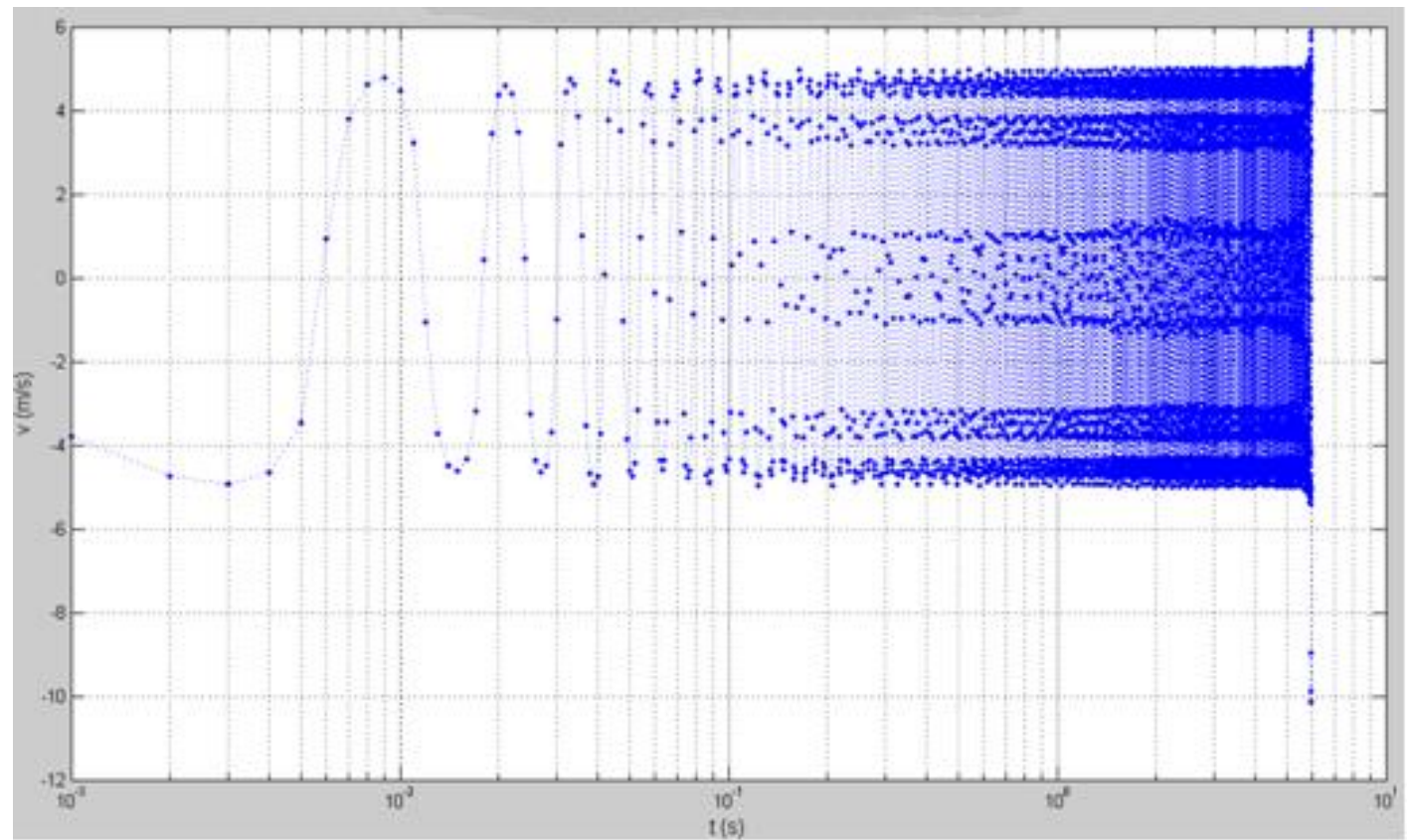

(b)

Gambar 3. Model perubahan fungsi waktu pada saat $y_{0}=0,010524 \mathrm{~m}$ (a) simpangan (b) kecepatan 
Berdasarkan model tersebut maka diketahui bahwa sistem osilator magnetik yang ditunjukkan pada gambar 3 bersifat nonlinear pada saat diberikan simpangan awal sebesar 0,010524 . Sehingga besarnya masukan awal sangat berpengaruh pada kestabilan sistem di waktu selanjutnya. Peristiwa tersebut juga terdapat pada sistem pegas dan bandul matematis. Permasalahan yang masih belum dapat dipecahkan dalam penelitian ini adalah tidak diketahuinya kapan sistem tersebut akan berhenti berosilasi. Pada kenyataannya semua gerak osilasi akan berhenti karena energi mekanik terdispersi akibat adanya suatu gaya gesekan. Jika gaya gesekan atau redaman kecil, maka gerak hampir periodik dan amplitudo akan berkurang secara lambat terhadap waktu. Namun pada penelitian ini tidak terjadi peristiwa penurunan amplitudo walaupun waktu telah berubah selama $1000 \mathrm{~s}$. Untuk menganalisis hal tersebut perlu ditinjau faktor redaman pada osilator magnetik tersebut.

Pembahasan ditulis melekat dengan data yang dibahas. Pembahasab diusahakan tidak terpisah dengan data yang dibahas,

\section{KESIMPULAN}

Berdasarkan hasil dan pembahasan penelitian yang telah dilakukan, maka dapat diambil kesimpulan bahwa dari metode NewtonRaphson diperoleh nilai jarak antara magnet statis 1 dengan magnet utama sebesar $0,01512559816833 \mathrm{~m}$. Adapun dari metode Euler didapatkan model osilator magnetik mulai nonlinear pada saat diberikan simpangan $0,010524 \mathrm{~m}$. Belum adanya faktor redaman sehingga persamaan gerakpada osilator magnetik harus ditinjau ulang.

\section{DAFTAR PUSTAKA}

Bronson, R., \& Costa, G.B., (2007), Persamaan Differensial, edisi ke-3, Erlangga.

Hartono, R. F. Abdullatif., Nanda D.F., (2011), Rancang Bangun Sistem Deteksi Dini Tanah Longsor Menggunakan Sensor Getaran Berbasis Induksi Elektromagnetik, (laporan penelitian DIPA, Universitas Jenderal Soedirman).

J. Aminuddin, (2008), Dasar-Dasar Fsika Komputasi Menggunakan MATLAB, Yogyakarta : Gavamedia.

Kiusalaas, J., (2005), Numerical Methods in Engineering with MATLAB, Cambridge University Press.

Kuczmann, M., (2008), The Polarization Method Combined with the NewtonRaphson Technique in Magnetostatic Field Problems, PRZEGLAD ELEKTROTECHNICZNY, Hungary.

Longair, M., (2003). Theorethical Concepts in Physics. (2 $\left.{ }^{\text {th }} e d.\right)$. Cambridge University Press.

Mardiana, (2010), Penentuan Kriteria dalam Menyelesaikan Persamaan Diferensial Sturm-Liouville dengan Metode Euler, (skripsi, Fakultas Matematika dan Ilmu Pengetahuan Alam, Universitas Sumatera Utara, Medan). 